\title{
A PROVA ECONÔMICA NA ANÁLISE DE ATOS DE CONCENTRAÇÃO EM MERCADOS DE COMPETIÇÃO DINÂMICA
}

\author{
Isabella Dorigheto Miranda* \\ Juliana Oliveira Domingues ${ }^{* *}$
}

Resumo: Por meio de abordagem exploratória e raciocínio dedutivo pautado em revisão bibliográfica, procura-se apontar a importância da prova econômica na análise de atos de concentração pelo CADE, considerando o aumento dessas operações em mercados de competição dinâmica, marcados por elevado nível de inovação. Referida prova assume relevância argumentativa e se propõe a estipular o efeito líquido negativo da operação. Considera-se que a prova econômica embasaria o argumento econômico de aplicação normativa, inserindo-se na análise econômica do direito. Ao trabalhá-la em mercados de inovação deve-se estar ciente das limitações legais existentes, bem como dos desafios do ambiente digital.

Palavras-chave: Atos de Concentração; Condutas Anticompetitivas; Prova Econômica; Inovação; Competição Dinâmica.

\section{ECONOMIC PROOF IN MERGER REVIEWS FOR DYNAMIC COMPETITION MARKETS}

Abstract: Through an exploratory approach and a deductive rationale based on literature review, one aims to point the economic proofs' importance in merger reviews by CADE, considering the increase of operations in dynamic competition markets characterized by high levels of innovation. Such proofs assume rhetoric relevance, aiming to stipulate the transaction's negative net effect. This study considers that the economic proof would base the economic argument on the normative enforcement, inserting the discussion on law and economics. When working with economic proofs in innovation markets one should be aware of the legal limitations, as well as to the digital environment challenges.

Keywords: Mergers; Anticompetitive Conducts; Economic Proof; Innovation; Dynamic Competition.

\section{Introdução}

Os atos de concentração no Brasil passam, desde a Lei nº 12.529/2011, por análise prévia da autoridade de defesa da concorrência, o Conselho Administrativo de Defesa Econômica (CADE). Ao determinar a submissão ao órgão, a legislação brasileira insere o controle de estruturas na vertente preventiva de sua atuação, o que significa que o objetivo da autoridade concorrencial é de evitar a concretização de operações, ou trocas de dados e

\footnotetext{
* Mestranda em Direito e Desenvolvimento pela Universidade de São Paulo (FDRP-USP). Advogada. Bacharel em Direito pela Universidade de São Paulo (FDRP-USP). E-mail: isabella.miranda@usp.br.

** Professora Doutora da Universidade de São Paulo (FDRP-USP), Secretária Nacional do Consumidor do Ministério da Justiça e Segurança Pública. E-mail: julianadomingues@usp.br.
} 
informações comercialmente sensíveis, que lesem o ambiente competitivo de maneira que dificilmente possa ser controlada ou desfeita (DOMINGUES, GABAN, 2016, p. 123-164).

Busca-se, dessa maneira, evitar a ocorrência de efeitos danosos permanentes à ordem concorrencial elegida pelo arcabouço jurídico brasileiro - considerando, também, os preceitos da Constituição Federal de 1988, especialmente os princípios da livre iniciativa e da livre concorrência, esculpidos no art. 170 da Constituição Federal ${ }^{1}$. A averiguação e a decisão sobre o prosseguimento ou não de um ato de concentração, contudo, depende de variáveis que, por ora, se concentram no critério eficientista, especialmente no quesito preço (consumer welfare), e nos efeitos após a operação. Passa-se, assim, pela definição de um mercado relevante, com base no teste do monopolista hipotético, definindo se o poder de mercado do agente envolvido na operação poderia ser ampliado de maneira a prejudicar o ambiente concorrencial (DOMINGUES, GABAN, 2016, p. 106-112).

Destaca-se, contudo, que o mero fortalecimento de posição comercial (ainda que dominante) não é, per se, considerado um ilícito na legislação brasileira. Por meio da "regra da razão", averígua-se tanto os potenciais resultados do ato quanto o intuito (objetivos) das partes envolvidas. Assim, diante de potencial conduta de abuso de posição dominante e mesmo à luz do controle de condutas da lei antitruste, "é necessário apurar-se que resultam efeitos líquidos negativos para que atos empresariais lesivos à concorrência possam ser objeto de condenação" (DOMINGUES et al., 2018). Nesse cenário, a análise de efeitos assume maior relevância para a autoridade, que deve, contudo, adotar a norma jurídica como fundamentação última de seu processo decisório.

Para mercados de competição dinâmica e, principalmente, para atos de concentração que envolvem a aquisição e/ou modificação da estrutura societária de um agente inovador, seja ele um rival estabelecido, potencial ou emergente, a análise tradicional pode se mostrar inadequada. Há, nessas situações, a presença de efeitos estranhos ao preço, tal como qualidade e inovação, como quesitos centrais.

Considere-se, por exemplo, a situação de determinada empresa que desenvolve um produto no setor financeiro que poderia, no futuro, torná-la uma concorrente de firmas já estabelecidas (caracterizando um rival potencial, ou entrante). Nesse cenário, a inovação atuaria como "choque exógeno" (LYRA, 2016, p. 49) ao mercado, ou seja, como a inserção de um fator extrínseco ao seu funcionamento regular. Ao estudar o mercado, participantes

\footnotetext{
${ }^{1}$ Neste sentido, cf. Domingues e Gaban (2019, p. 111-130).
} 
atuais poderiam facilmente, pelo uso tanto de recursos financeiros quanto de seu poder atual (caso existente), decidir pela aquisição da firma, com consequente incorporação do produto ou supressão de suas atividades regulares. Além disso, é mais provável que as firmas incumbentes tenham maior facilidade de identificar concorrentes potenciais, dada a organização empresarial e a condução regular de seus negócios (KATZ, 2020, p. 9).

No caso de supressão total das atividades e produtos da firma inovadora, na qual o mercado se vê privado de um novo agente e de resultados que poderiam se provar benéficos aos consumidores, há claro dano potencial à concorrência. Entretanto, como se pode provar que a permanência da firma inovadora no mercado seguiria caminho diverso caso o agente estabelecido não interferisse no mercado?

Em primeiro lugar, em homenagem ao princípio da livre iniciativa, parte-se do pressuposto de que qualquer intervenção - regulatória, in casu - deve ser estritamente necessária e justificável (DOMINGUES, GABAN, 2019, p. 111-130). A análise tradicional antitruste voltar-se-ia para a variável preço, pressupondo um cenário futuro a partir de determinado recorte da realidade no momento em que o ato de concentração ocorreu. Ademais, a operação somente seria obrigatoriamente analisada, previamente pelo CADE, caso fosse cumprido o critério faturamento (conforme explicado na seção 2). Para agentes inovadores, existe um risco real de não se enquadrarem nesses requisitos, tal como o caso entre Facebook e Whatsapp no Brasil ${ }^{2}$, o que tornaria as operações inicialmente "invisíveis" para a autoridade concorrencial, ou apenas sujeitas a um futuro controle de condutas.

A discussão liga-se, ainda, à análise de eficiências que podem derivar dos atos de concentração analisados. Especificamente para mercados de competição dinâmica, a introdução de inovações pode ser considerada fonte de eficiências pelo potencial de gerar quedas futuras de custos das firmas e preços para os consumidores ou outras melhorias. Nesse sentido, Sato (2015, p. 84-85) destaca o AC 08012.003296/2007-78, na análise do qual o CADE reconheceu que há maior complacência a concentrações verticais que apresentem conjunto de eficiências ligadas à inovação.

Ademais, em alguns casos os efeitos adversos de uma fusão em variáveis estranhas ao preço podem assumir relevância equivalente ou superior a ele (KWOKA, 2020, p. 84). Entretanto, há verdadeira incerteza quanto à concretização desses efeitos, o que é agravado em situações nas quais há um competidor em potencial ou emergente, cuja participação no

\footnotetext{
${ }^{2}$ Nesse sentido, Domingues (2019). Ver também Arruda, Pinedo e Mondeck (2018, p. 37).
} 
mercado ainda não gerou subsídios suficientes para análise e para o qual não há histórico precedentes - que possa ser considerado.

Portanto, dada a tradicional análise antitruste, baseada na escola de Chicago (DOMINGUES, GABAN, 2016, p. 88-93) ${ }^{3}$ a aferição pela autoridade antitruste desses benefícios envolverá, muito provavelmente, a prova econômica. Tem-se, portanto, cenário de interação entre as predições legais e a utilização da economia (especialmente a Análise Econômica do Direito - AED) como ferramenta adicional. Contudo, deve-se manter a visão de que a sobreposição de preceitos econômicos e a utilização de testes e premissas diversas podem gerar resultados também diferentes, a depender do que for eleito pelo aplicador dos modelos. Por exemplo, sob a ótica da escola de Chicago, caso se prove que o bem-estar agregado aumentaria após a operação, ela teria consequências mais benéficas ao mercado do que o impedimento do ato, sem que fosse necessário considerar potencial distributivo das benesses e, portanto, deveria ser aprovada sem restrições pela autoridade.

Logo, é necessário avaliar as questões que podem envolver a utilização da economia como ferramenta para análises de mercados de competição dinâmica, a fim de delimitar as possíveis interações e limites frente às disposições legais a serem aplicadas pelas autoridades antitruste. Esse é, dessa forma, o objetivo central deste trabalho.

Para tanto, ele será dividido em três seções principais. A primeira se dispõe a explicitar como é realizada no Brasil, atualmente, a análise dos atos de concentração submetidos ao CADE. Passa-se, assim, pela enumeração dos critérios utilizados pelo CADE, bem como pela exploração do racional econômico tradicional envolvido na proteção da concorrência.

A segunda seção refere-se ao estudo dos mercados de competição dinâmica e, mais especificamente, ao problema dos competidores potenciais e emergentes, especialmente nos mercados digitais. São indicadas as principais características relacionadas a tais situações, com foco no potencial inovador, destacando o aumento de elementos de incerteza envolvidos na organização industrial. Em seguida, elegem-se os competidores potenciais e os emergentes enquanto ameaças às firmas estabelecidas, de maneira a deixar clara a problemática que pode envolver atos de concentração que os tenham enquanto participantes.

\footnotetext{
${ }^{3}$ Nesse sentido, Domingues e Klein (2020, p. 83), ao explicar os efeitos das críticas da Escola de Chicago no Direito da Concorrência, destacam que houve a construção "[...] de uma nova teoria microeconômica e de Organização Industrial pela Escola de Chicago", com o "sucesso desse movimento no Direito da Concorrência".
} 
Finalmente, já delineado o cenário, a prova econômica é apresentada como ferramenta para as autoridades antitruste. Entretanto, são explicitados os problemas e potenciais limites que tal intersecção entre direito e economia podem enfrentar, em específico considerando os possíveis limites jurídicos de sua aplicabilidade quando em cenários de incerteza, diante da presença de inovação.

\section{Breve exposição sobre a análise de atos de concentração no Brasil}

A legislação concorrencial brasileira (Lei 12.529/2011) introduziu uma novidade na análise de atos de concentração, consubstanciada na figura da análise prévia de atos de concentração pelo CADE. A partir de sua vigência, os agentes envolvidos devem notificar a autoridade antes de celebrarem "uma fusão, uma incorporação ou outras operações que alterem a estrutura dos mercados" (BACCHI, SCHAPIRO, 2013, p. 50). A obrigatoriedade da submissão, contudo, é vinculada a um determinado patamar de faturamento no Brasil das firmas envolvidas, ou de seus grupos econômicos, adotado enquanto critério objetivo pela Lei Antitruste.

Dessa maneira, um ato de concentração deve ser necessariamente notificado previamente ao CADE se, cumulativamente, uma das partes tiver um faturamento mínimo ou volume de negócios no país de R \$750.000.000,00 (setecentos e cinquenta milhões de reais) e a outra de $\mathrm{R}$ \$ 75.000.000,00 (setenta e cinco milhões de reais). Inicialmente, não há menção expressa ao critério de mercado relevante, mas o CADE trabalha sua definição como etapa para análise de atos de concentração (CADE, 2016) em guia específico. Para tanto, são utilizados, dentre outros aspectos econômicos, o teste do monopolista hipotético, símile à experiência europeia com o SSNIP test (small but significant and non-transitory increase in price). Em resumo, a ferramenta avalia se, após a operação, ocorreria uma mudança de preço, não transitória, por conduta unilateral da empresa resultante, da qual a firma estabelecida poderia se aproveitar, em detrimento dos consumidores finais, o que se assemelha a uma verificação de exercício de lucros extraordinários (monopolistas).

Ressalva-se que o intuito da legislação brasileira não é o de coibir o crescimento das empresas pela condução regular de seus negócios. A formação de poder de mercado não é considerada um ilícito a princípio, desde que esse seja alcançado por um diferencial competitivo legítimo (GUERRIERO, 2008, p. 8), sem a utilização de condutas e estratégias anticoncorrenciais, que prejudiquem o mercado e/ou competidores indevidamente. Dessa maneira, o controle dos atos de concentração e as análises envolvidas objetivam, "evitar a 
formação de estruturas inadequadas de poder econômico" (BACCHI, SCHAPIRO, 2013, p. 51), preservando o ambiente concorrencial.

Conforme explanado, as diretrizes atuais do CADE demonstram, em última instância, a utilização de ferramentas econômicas, dentre as quais o teste do monopolista hipotético, como referencial para auxiliar a autoridade na aprovação ou não dos atos de concentração. Sob tal afirmação, complementa-se a discussão com a explicitação do racional econômico tradicional de proteção da concorrência, na seção abaixo, explicitando alguns conceitos.

\subsection{A lógica microeconômica tradicional de proteção à concorrência}

Os fundamentos econômicos tradicionais que explicam os mercados e as relações de concorrência voltam-se, majoritariamente, para os princípios de microeconomia. Assim, em um modelo de "concorrência perfeita", no qual nenhuma das firmas envolvidas no mercado pode unilateralmente ditar as tendências de preço, os ofertantes de produtos e serviços são vistos como tomadores de preço.

Como explicam Schapiro e Bacchi (2013, p. 52), os consumidores teriam o bem ao qual dariam maior valor, ao passo em que as empresas teriam recebido o valor monetário correspondente. Ter-se-ia, dessa forma, "uma situação ótima de bem estar social" ${ }^{\text {, em visão }}$ que claramente remete à escola de Chicago, tomando a eficiência alocativa como sinônimo ao bem-estar social ${ }^{5}$.

Outra seria a situação de um mercado monopolista, no qual a firma teria o poder unilateral de estabelecer o preço, já que inexistiriam competidores aos quais os consumidores pudessem recorrer. Nessas situações, além da elevação de preços e redução de quantidades, terse-ia o que se convencionou chamar de deadweight loss. Esse seria um custo criado pela ineficiência de mercado, representado por um valor que não é alocado para nenhum dos envolvidos na relação mercantil. A hipótese é de que, no momento em que oferta e demanda estão desequilibradas, a alocação deixa de ser eficiente.

\footnotetext{
${ }^{4}$ Nela, "ocorrem as seguintes equivalências: (i) o preço pago equivale ao custo marginal; (ii) o custo marginal do ofertante iguala-se à sua receita marginal; e (iii) o preço estipulado para o consumidor corresponde à utilidade marginal que ele atribui ao bem adquirido" (BACCHI, SCHAPIRO, 2013, p. 52). Ver também Domingues e Gaban (2016, p. 88-104) e Nusdeo (2014, p. 183-226).

${ }^{5}$ Nas palavras de Robert Bork (1978, p. 7-8), "business efficiency necessarily benefits consumers by lowering the costs of goods and services or by increasing the value of the product or service offered; this is true whether the business unit is a competitor or a monopolist".
} 
Além disso, a formação de um mercado monopolista teria ainda outro custo a ser considerado: a posição de monopólio permite à firma obter lucros extraordinários, que não seriam atingidos em um cenário de concorrência (COOTER, ULEN, 2012, p. 29-31). Dessa forma, uma parte dos recursos deixaria de ser alocada entre os agentes envolvidos, para ser empregada em comportamentos defensivos do monopolista. Esses podem incluir diversas estratégias, tais como diferenciação predatória de produtos, captura de agentes governamentais e busca de facilidades legais (BACCHI, SCHAPIRO, 2013, p. 55).

Portanto, a defesa da concorrência teria como objetivo último, sob a visão tradicional, a manutenção e promoção de um cenário de eficiência alocativa, no qual os recursos da sociedade seriam repassados àqueles que lhes dessem maior valor. Em última instância, um cenário de menor competição seria desejável apenas nas situações em que ocorresse uma troca em termos de eficiência. Há a crítica, contudo, de que não se trabalha o aspecto distributivo da alocação de recursos sob a lógica tradicional de microeconomia ou na análise tradicional das eficiências que poderiam compensar a redução da competitividade.

Assim, ao longo do último século, as contribuições das escolas de Chicago e de Harvard, essa voltada para uma perquirição estruturalista, e esse racional microeconômico influenciaram as análises de atos de concentração pelas autoridades antitruste ${ }^{6}$, sendo que, atualmente, passamos a uma nova fase, na qual ideias consideradas "populistas" ressurgiram diante do crescimento das Big Techs (DOMINGUES, GABAN, 2019, p. 222-244).

\subsection{Reflexos do racional econômico na análise de fusões e aquisições}

A análise dos atos de concentração pela autoridade antitruste passa por diversas etapas, algumas delas diretamente dependentes do levantamento de dados econômicos a respeito das empresas envolvidas. Certas variáveis analisadas, em particular, são essenciais para a aprovação ou não da operação, dentre as quais estão inclusas a influência do número de competidores, o nível de concentração do mercado, a identificação das barreiras de entrada a novas firmas etc.

De forma geral, tais dados servirão para a autoridade determinar a probabilidade de, após a conclusão do ato de concentração, a firma adquirir e exercer "poder de mercado tanto unilateral quando coordenado (LYRA, 2016, p. 28-33). A análise é derivada da ideia de que a

\footnotetext{
${ }^{6}$ Sobre a relação entre as grandes escolas de análise antitruste e sua influência no direito concorrencial, cf. Domingues e Gaban (2016, p. 86-104).
} 
concentração do mercado poderia dar à firma estabelecida e monopolista a possibilidade de controle dos preços e das condutas mercantis, resultando em prejuízo aos consumidores.

Nesse sentido, a fusão internalizaria a concorrência entre os participantes do mercado. Como consequência, ter-se-ia redução da competição geral e das quantidades totais, ao passo em que se elevaria os preços, considerando também o efeito que a operação poderia ter sobre o comportamento dos agentes não diretamente envolvidos (GUERRIERO, 2008, p. 21).

Para averiguar essas possibilidades, a autoridade antitruste normalmente inclui uma etapa de análise do mercado na avaliação do ato de concentração. Nesse momento, faz-se a definição geográfica e de produto da atuação das firmas envolvidos, levantando dados como séries de preços, capacidade de oferta, elasticidade da demanda, etc. Ainda, a participação de mercado das empresas, normalmente definida pelas parcelas de faturamento total das firmas em comparação com o total no mercado, é um dos dados que costuma ser decisivo nas análises.

De acordo com Lyra (2016, p. 60), o paradigma atual da análise de fusões e aquisições reflete contribuições tanto da teoria estruturalista quanto da Escola de Chicago. Essas se traduzem no papel dado às questões estruturais para determinar os efeitos de fusões e aquisições e na avaliação de eficiências compensatórias, que levariam à aprovação do ato de concentração mesmo se a concorrência fosse diminuída.

Em resumo, pode-se afirmar que o formulador da política concorrencial é norteado pela busca de um arranjo que mais se aproxime do cenário de concorrência (BACCHI, SCHAPIRO, 2013, p. 55), para o que diversas premissas a respeito de eficiências e objetivos do antitruste podem ser levantados. Tendo em vista a realidade da atuação da autoridade de defesa da concorrência, bem como o cenário de assimetria de informações em que se encontra perante as firmas do mercado, a análise de atos de concentração pode envolver simplificações de regras e modelos econômicos.

Nesse sentido, Domingues e Klein (2020, p. 91-92) destacam que standards como o padrão de bem-estar do consumidor foram estabelecidos para mitigar resultados "paradoxais", derivados da aplicação de doutrinas diversas. Os autores reconhecem, contudo, que tal simplificação tem sido questionada atualmente, dado o avanço dos mercados digitais.

Especialmente para setores de competição dinâmica com a presença de competidores não estabelecidos, isso pode afetar o resultado do exame pela autoridade antitruste. Cabível, 
portanto, maior desdobramento sobre tais mercados, destacando as características que lhe são únicas.

3 Mercados de competição dinâmica: o problema dos competidores potenciais e dos não estabelecidos

Conforme estudado nas seções anteriores, a análise antitruste dos atos de concentração empresarial tem o objetivo de proteger um ambiente de concorrência, no qual o poder de mercado de uma firma não seja alcançado por meio de condutas anticoncorrenciais. Nesse sentido, cabe destacar que, mesmo antes da entrada em vigor da Lei ${ }^{\circ}$ 12.529/2011, quando o Sistema Brasileiro de Defesa da Concorrência (SBDC) era formado pela tríade SEAE/MF, SDE/MJ e CADE, a Portaria Conjunta SEAE/SDE n. 50, explicava que:

[...] o exercício do poder de mercado consiste no ato de uma empresa unilateralmente, ou de um grupo de empresas coordenadamente, aumentar os preços (ou reduzir quantidades), diminuir a qualidade ou a variedade dos produtos ou serviços, ou ainda, reduzir o ritmo de inovações com relação aos níveis que vigorariam sob condições de concorrência irrestrita, por um período razoável de tempo, com a finalidade de aumentar seus lucros (MINISTÉRIO DA JUSTIÇA, MINISTÉRIO DA FAZENDA, 2001).

Dessa maneira, é possível - ao menos em tese - que uma firma exerça poder de mercado em praticamente qualquer mercado em que atue desde que seja presumível seu poder unilateral. Em mercados de competição dinâmica, marcados por altos níveis de inovação, esses eventos se mostram mais desafiadores quando abarcam a ingerência em competidores potenciais ou não estabelecidos. Deve-se considerar que, nesses ambientes, as firmas competem para oferecer novos produtos, processos ou modelos de negócios. Embora seja relacionada normalmente com a presença de alta tecnologia, elevada taxa de inovação e com a necessidade de pouco capital inicial, a competição dinâmica pode ocorrer, praticamente, em quaisquer mercados. Entretanto, é impossível negar que a atuação de firmas como as big techs, com "uso intensivo de novas tecnologias e plataformas de múltiplos lados" (SAITO, 2016, p. 9), tem trazido questionamentos quanto à aplicação tradicional do antitruste, o que tem gerado um resgate ao movimento "neo-brandeisiano" também chamado de movimento "populista" ou "hipster antitruste"

\footnotetext{
${ }^{7}$ Nesse sentido, "o movimento "neo-brandeisiano" segue fortalecido diante do crescimento dos mercados digitais e consequente poder econômico emanado pelas empresas de tecnologia ou High Tech 'Trusts. Resta
} 
De maneira geral, o racional econômico e as análises realizadas para a aprovação de atos de concentração envolvem, majoritariamente, análise da posição das firmas no mercado, bem como variáveis como o preço dos produtos e serviços. Por exemplo, operações que resultassem em aumentos exacerbados de custos para os consumidores, com concentração econômica, teriam já o prejuízo "comprovado". Entretanto, em cenários de competição dinâmica, o processo concorrencial pode estar centrado em outras variáveis, como a inovação realizada pelas firmas (LYRA, 2016, p. 13).

Especialmente com relação à interação entre as firmas estabelecidas e competidores potenciais ou emergentes, a análise e a construção de um racional voltado para o preço dificilmente refletirão a realidade do mercado. Nesse sentido, Katz (2020) destaca que em ambientes em que as margens de lucro são relativas à diferenciação dos produtos, como costumam ser os mercados de competição dinâmica, o processo competitivo pode ser pelo mercado; ou seja, não no mercado.

Nessas situações, as firmas competem por meio de inovação. Assim, competidores potenciais ou emergentes precisam adquirir ativos complementares, além de atingir uma trajetória de crescimento promissora, para se firmarem no mercado.

Contudo, essa característica faz com que as firmas estabelecidas tenham maior facilidade em identificar rivais potenciais e emergentes, antes que atinjam a posição de competidores efetivos (KATZ, 2020, p. 1-2) e os adquiram, ou estabeleçam barreiras de entrada mais rígidas, dificultando a atuação de empresas entrantes. Para atos de concentração que ocorram dessa maneira, o preço não pode ser observado como de costume, já que, muitas vezes, nem mesmo o faturamento das firmas representa o potencial adquirido ${ }^{8}$.

Lyra (2016, p. 56) traz à tona a discussão sobre a adoção de uma alternativa às eficiências alocativas estáticas, que seria o uso de eficiências dinâmicas. Nessas, estariam incluídos elementos intertemporais para análise, deixando de lado a visão de curto prazo das

agora saber se os paradigmas do direito antitruste serão refinados ou não diante das incertezas lançadas pelas discussões diante de um mercado cada vez mais dinâmico, digital e disruptivo" (DOMINGUES, GABAN, 2019, p. 239).

${ }^{8}$ Discussão como essa foi levantada pela Conselheira Cristiane Alckmin na análise do Ato de Concentração 08700.004431/2017-16, que versava sobre a aquisição de participação no capital social da XP Investimentos pelo Banco Itaú. Apesar da preocupação expressa no voto da Conselheira sobre os riscos da aquisição de empresas de alta disruptivas, Ana Frazão e Angelo Gamba Prata de Carvalho (2019, p. 39) destacam que a discussão sobre concorrência potencial foi apenas tangenciada pelo CADE, não assumindo caráter central na decisão. Para a autora "a análise concorrencial deve estar especialmente atenta às aquisições de agentes inovadores". 
consequências da operação: uma piora no presente poderia ser um custo aceitável se, em troca, ocorresse um aumento de eficiência no futuro.

Apesar disso, o autor destaca que esse modelo também não seria adequado para mercados com forte inovação: o foco permaneceria na melhor eficiência alocativa, representada tradicionalmente por critérios que representam a concorrência em preços ou quantidades, ao passo em que outras características, tais como qualidade, inovação envolvida ou até mesmo uso de dados seriam desconsideradas.

[...] a análise de fusões e aquisições [...] procura buscar sempre a alocação de recursos que gere a melhor eficiência alocativa, segundo os critérios de Pareto. Portanto, se concentra nos efeitos que a fusão ou aquisição terá, predominantemente, na variável preços de mercado e com um viés estático, sem considerar o longoprazo. Esse tipo de análise pode ser prejudicial em muitos casos onde a variávelchave do processo competitivo é a inovação (LYRA, 2016, p. 60).

Claro, portanto, que o cenário atual, no qual cada vez mais mercados passam por um processo de digitalização e começam a interagir em processo de competição dinâmica, propõe desafios para a análise tradicional dos atos de concentração. Em verdade, a própria ação de inovar está intimamente ligada ao futuro. No ambiente empresarial, essa capacidade pode representar a dominação rápida de um mercado, especialmente porque os efeitos de atos de concentração ligados a qualidade, custos, variedade, pesquisa e desenvolvimento e inovação são tipicamente valorizados pelos consumidores e, dessa forma, representam variáveis de importância estratégica para as firmas (KWOKA, 2020, p. 84).

Entretanto, a análise de atos de concentração, nesses casos, e os testes realizados para averiguar os possíveis prejuízos advindos, raramente focam na perda de potencial e estabelecimento de futura concorrência. Há, nessa situação, um característico cenário de incerteza, no qual o racional lógico-econômico estaria carente de dados prévios. Além disso, a depender do momento em que a firma incumbente identifica e adquire um competidor emergente/potencial, mais difícil se torna para a autoridade desafiar a operação e mais rapidamente a empresa com poder de mercado pode evitar concorrer com outras (KATZ, 2020, p. 9).

Explicitado o ambiente, deve-se ter em mente que tanto a argumentação econômica quanto jurídica é dependente de um determinado discurso, do qual deve-se ter as premissas claras. Da mesma forma, há quem defenda que a análise econômica do direito aplicada ao antitruste será retórica (MCCLOSKEY, 1988, p. 761), com resultados dependentes das 
premissas adotadas. Assim, tanto a análise do mercado quanto a argumentação levantada pelas partes devem obedecer aos limites impostos pela ordem jurídica. Cabe destacar que, ao menos na atualidade, a utilização de provas econômicas ainda é um importante instrumento levantado pelos envolvidos na investigação, contribuindo para a decisão da autoridade antitruste. Nesse sentido, Domingues e Klein (2020, p. 97-99) destacam que diversos autores, como Hovenkamp e Orbach e Rebling sustentam que "a análise [econômica] deve se basear em critérios econômicos objetivos e mensuráveis", mas não perdeu sua importância frente às críticas do movimento "neo-brandeisiano", já que a aplicação do antitruste requer “instrumentos seguros de análise”.

\section{A prova econômica em cenários não preditivos}

$\mathrm{Na}$ análise de atos de concentração, as autoridades realizam o que se identifica como controle "prévio" de estruturas, ou seja, trata-se do eixo preventivo de atuação".

$\mathrm{Na}$ experiência brasileira, a notificação é obrigatória de acordo com os critérios explicitados na seção 2, baseados em faturamento dos grupos econômicos. A partir de então, o órgão antitruste realiza o exame seguindo um roteiro de análise de dados e informações prestados pelas empresas e seus grupos econômicos (partes da operação) podendo, também, solicitar dados adicionais provenientes de terceiros. Tais dados servem de subsídios para a análise antitruste, devendo pautar os fundamentos da decisão final que poderá ser da Superintendência Geral (nos casos de rito sumário) ou do Tribunal do CADE, em casos de rito ordinário (DOMINGUES, GABAN, 2016, p. 159-161).

Contudo, a análise do CADE deve seguir os limites da legislação antitruste brasileira. Na notificação da operação, geralmente - e especialmente em casos mais complexos - provas econômicas são utilizadas tanto pelas firmas (partes da operação - i.e. ato de concentração) quanto pelas autoridades como ferramenta para o convencimento e fundamentação. Relevante, portanto, que exista essa discussão atual sobre eventuais limitações e parâmetros, especialmente em cenários de incerteza causados por mercados digitais e disruptivos.

\subsection{As escolas de Harvard e de Chicago como paradigmas}

\footnotetext{
${ }^{9}$ Aqui, Bacchi e Schapiro (2013, p. 56) identificam dois passos principais: identificação e sancionamento. O primeiro ocorreria pela notificação dos atos que poderiam repercutir na estrutura do mercado; o sancionamento ocorreria somente para as operações nas quais os custos à manutenção da concorrência fossem superiores aos benefícios advindos.
} 
Conforme explicitado na seção 2, a aplicação do antitruste encontrou explicação no racional econômico de diversos estudiosos. Dentre eles, duas correntes se destacaram na figura das escolas de Harvard e de Chicago, a primeira focada no estudo das estruturas de mercado e a segunda na análise de eficiências compensatórias da redução da concorrência.

Dessa forma, a escola de Harvard vê a relação entre concorrência e a formação de estruturas no ambiente empresarial, buscando explicar a existência e o resultado de oligopólios. Ao fazê-lo, relaciona poder de mercado com fatores estruturais, já explicitados acima, tais como: nível de concentração de mercado, diferenciação de produtos, barreiras de entrada etc. Esses elementos teriam relevância preponderante para explicar o desempenho dos mercados, bem como o modo como estariam organizados em termos de participação e atuação empresarial.

Por sua vez, a escola de Chicago foca especialmente nas eficiências que poderiam advir dos atos de concentração econômica. Assim, a redução da concorrência poderia ser aceita caso se comprovasse que a alocação de recursos na sociedade permaneceu em nível "ótimo", ou seja, que cada envolvido no mercado teve por resultado aquilo para o que concedia maior valor. É possível, portanto, que o aumento de preços e a perda de concorrência seja compensada por um aumento de eficiência (aqui vista como maximização da capacidade alocativa e, muitas vezes, tratada como maximização do bem-estar social agregado por autores dessa corrente). Bork (1978, p. 28), por exemplo, destaca que acordos de eliminação de rivais, ainda que explícitos, devem ser encorajados caso tornem a integração essencial entre firmas mais eficientes.

Lyra (2016, p. 19-20) destaca que, do ponto de vista econômico, o paradigma atual utilizado pela política antitruste na maior parte do mundo seria melhor enquadrado como uma corrente "Pós-Chicago". Nela, estariam sintetizados elementos centrais das escolas de Harvard e de Chicago, assumindo uma posição intermediária entre "o intervencionismo de Harvard e o laissez-faire de Chicago". De fato, em muitas jurisdições é possível encontrar, como no Brasil, a coexistência de ilícitos antitruste per se, pautados na formação de determinadas estruturas empresariais no mercado (como carteis), e o uso do que se chama de "regra da razão", pela qual a conduta será coibida a depender dos efeitos danosos à concorrência que forem aferidos.

A explicitação desses paradigmas é relevante especialmente quando da utilização de provas econômicas. Por vezes, a economia é tratada pelas partes envolvidas e pelos órgãos de 
defesa da concorrência como última palavra. Em um país que é fortemente pautado pelo dogmatismo jurídico - como o Brasil - há também o argumento jurídico que pode entrar em choque com os argumentos eficientistas sobre a necessidade de aprovação ou não do ato de concentração ${ }^{10}$.

Em verdade, as premissas adotadas refletem até mesmo no objetivo atribuído à política antitruste pelos economistas - o que explica a diferenciação entre as escolas de Harvard e de Chicago. Dessa forma, não é surpresa que também impactem nos resultados da utilização da prova econômica, consubstanciada, por exemplo, em modelos teóricos e matemáticos a respeito dos efeitos de atos de concentração. Como destacam Domingues e Klein (2020, p. 99),

a AED como movimento teórico não se resume na versão fundacional Posneriana e atualmente é bastante plural, incorporando propostas teóricas diversas, tais como a economia comportamental, a public choice, a economia dos custos de transação, o institucionalismo original e a economia experimental.

Tendo em vista a diversidade de premissas e teorias econômicas que podem ser adotadas para análise de atos de concentração e o incremente constante de modelos econômicos, vê-se que a mera distinção entre Chicago e Harvard não exime as partes envolvidas na operação do esclarecimento dos fundamentos adotados na construção da prova econômica. Tais paradigmas, apesar de essenciais na doutrina antitruste, são constantemente alterados pela evolução tanto da ciência econômica quanto da ciência jurídica.

\subsection{Dificuldades do uso de modelos matemáticos em mercados de inovação para a análise antitruste}

A prova econômica na prática antitruste normalmente se consubstancia como modelo matemático aplicado ao mercado envolvido na operação. Guerriero (2008, p. 31) destaca que os resultados dessas ferramentas dependerão das premissas adotadas por quem os aplica, bem como da estrutura de interação elaborada. Para o autor, "em boa medida, o resultado do jogo já está determinado pela sua própria formulação”. Assim, deve-se sempre ter em mente as variáveis envolvidas na análise, bem como o objetivo da parte que apresentou a prova, ou seja, qual o ponto que ela busca sustentar. Além disso, todo modelo econômico pode ser

\footnotetext{
${ }^{10}$ De acordo com Maccloskey (1988, p. 753): "É preciso, entretanto, antever para além do discurso de que a economia é "dialética [...] e, portanto, lógica em um sentido moderno, ao passo em que o direito seria retórico".
} 
considerado como uma simplificação da realidade e nem sempre conseguirá traduzir o funcionamento de um mercado de maneira realista. Nesse sentido,

as relações econômicas reais são bastante sofisticadas e por vezes podem envolver muitas dimensões, dificultando seu tratamento analítico. Nesses casos, o uso de modelos muito simplificados pode invalidar os resultados das simulações como representativos do futuro provável (GUERRIERO, 2008, p. 6).

Explicitadas as dificuldades iniciais do uso de modelos econômicos, quais sejam, a utilização de variáveis e premissas específicas e a subjetividade envolvida na escolha da relação a ser analisada, é relevante destacar que não afetam sua utilidade enquanto ferramentas. Modelos simples, que possam ser replicados, permitem a conferência dos resultados, bem como sua compreensão pelas partes e pelas autoridades antitruste (desde que estejam claras as seleções realizadas durante a formulação).

Enquanto prova, os modelos econômicos são apresentados ao órgão antitruste para que este os sopese frente ao arcabouço jurídico que rege a matéria. Tendo em vista o uso da regra da razão, especialmente em atos de concentração econômica, nos quais a verificação de efeitos é retórica frequente, a autoridade se vê em posição difícil. A assimetria de informações frente às partes envolvidas na operação, bem como a necessária exposição dos parâmetros utilizados para a formulação das provas apresentadas para que seja possível considerá-las adequadamente na tomada de decisão, resulta em espaço para a autoridade antitruste exercer alguma subjetividade no resultado da análise, o que se liga a discussões atuais sobre valores e premissas que devem ser utilizados na aplicação do direito concorrencial ${ }^{11}$.

Feitas as devidas ressalvas, Guerriero (2008, p. 19) afirma que todas as simulações matemáticas em antitruste seguem as mesmas etapas, que poderão considerar variáveis e premissas diversas. Tem-se, de maneira geral: (i) a definição do mercado atual; (ii) a escolha de um modelo de oligopólio; (iii) escolha de uma forma da função de demanda; e (iv) definição do mercado pós-fusão. Após a última etapa, seria possível comparar o mercado atual com o resultante do ato de concentração e, a partir daí, assumir conclusões normativas. Veja-se que cada fase envolve uma multiplicidade de escolhas. A exemplo, na definição de

${ }^{11}$ Domingues e Klein (2020, p. 103) destacam que "mesmo que alguns desses critérios deixem de ser exclusivamente econômicos, não há dúvida de que a teoria econômica e a AED [...] serão decisivas na busca pela eficácia do Direito Concorrencial nos desafios surgidos na economia atual". 
mercado se estudam os produtos e serviços envolvidos, possíveis substitutos, os preços, os concorrentes, a participação de mercado de cada participante etc.

Especificamente no caso dos competidores potenciais e emergentes, tanto as partes quanto as autoridades estarão carentes de informações como demanda e custos, necessariamente implícitas nas etapas acima definidas. A previsão do futuro após a conclusão do ato de concentração é, portanto, dificultada, levantando questionamentos sobre a adequação das provas econômicas tradicionais para operações que ocorram em mercados de inovação. Nesse sentido, Kwoka (2020, p. 85) destaca que a teoria e as evidências econômicas ligadas ao efeito de atos de concentração sobre qualidade, variedade, pesquisa e desenvolvimento e mudança tecnológica são mais complexas, ao passo em que suas implicações geralmente se mostram mais ambíguas.

Katz (2020, p. 19), por exemplo, traça um estudo pelo qual conclui que, em mercados nos quais a concorrência exibe efeitos de rede, uma política permissiva a atos de concentração pode tanto (i) aumentar os incentivos da firma entrante para desenvolvimento de produtos, quando a firma resultante adota a tecnologia do entrante; quanto (ii), reduzir tais incentivos, quando se mantém a tecnologia da firma incumbente. O efeito do ato de concentração, nesse caso analisado sob o espectro dos estímulos à inovação, é totalmente dependente de escolhas futuras da firma resultante.

O autor ressalta, também, a possibilidade de que as firmas emergentes e/ou potenciais tenham iniciado suas atividades e desenvolvido seus produtos e serviços visando especificamente aquisição futura pela incumbente (KATZ, 2020, p. 21). Nesse cenário, ainda que se estudem os efeitos econômicos da concentração, a autoridade se encontra em uma situação na qual, muito provavelmente, caso o ato seja proibido, a firma emergente cessará suas atividades por completo.

Dessa forma, mais importante ainda que, na análise de atos de concentração que envolvam concorrentes potenciais e/ou emergentes, a prova econômica considere todos esses fatores, identificando especialmente as premissas adotadas. Sem dúvida alguma, decidir com base em dados e evidências é sempre mais seguro do que partir de argumentações dogmáticas ou retóricas e, nesse sentido, a prova econômica se mostra ferramental importantíssimo, mas não é infalível.

\section{Considerações Finais}


São grandes os desafios de todas as autoridades do mundo diante do poder econômico das grandes empresas de tecnologia e das naturais dificuldades de definição de mercado decorrente de suas especificidades ${ }^{12}$ em ambientes dirigidos por inovação, tal como se observa nos mercados digitais. Especialmente em cenários de incerteza, como o caso de atos de concentração em mercados de competição dinâmica envolvendo rivais potenciais ou emergentes, a utilização da prova econômica deve ser ferramenta aplicada no campo das provas. Contudo, consideradas as suas limitações, os debates e desafios atuais indicam que não é possível que seja adotada como única premissa de análise pelas autoridades ${ }^{13}$.

Ainda que, frente às modificações das relações empresariais, tais como a tendência de digitalização dos modelos de serviços, o crescimento de plataformas digitais e as alterações no padrão de comportamento dos consumidores, a legislação possa parecer insuficiente, é necessário que se explorem as alternativas fornecidas.

No Brasil, o controle de atos de concentração se insere no âmbito preventivo de atuação do CADE, a autoridade nacional de defesa da concorrência. Assumindo um racional microeconômico, a concentração no mercado e a assunção de posição dominante por uma empresa ou grupo econômico tem o potencial de gerar prejuízos aos consumidores diante de práticas tipificadas como infração à ordem econômica.

Assim, determinadas operações devem ser comunicadas previamente, a depender do faturamento das empresas e dos grupos econômicos envolvidos com base no art. 88 da lei 12529/2011. É possível a revisão de atos que não tenham se enquadrado nesse critério inicial, tal como estabelece o $\$ 7^{\circ}$ do referido artigo, assim como é possível a revisão de um ato já aprovado - em que pese não ser algo comum - conforme o art. 91.

\footnotetext{
${ }^{12}$ Domingues e Silva $(2018$, p. 42), ao analisar a relação entre fake news, mercados digitais e aplicação do antitruste, trazem que "o poder econômico emerge como um dos instrumentos mais efetivos de controle da sociedade e também dos consumidores. Ainda que imperceptível para muitos, vislumbra-se um efeito dominó: i. o processo de concentração econômica pode originar posição dominante nos mercados; ii. os agentes econômicos com poder econômico (decorrente de posição dominante nos mercados) têm o potencial de influenciar o Estado por meio de seus atos administrativos, políticos e instrumentos de regulação, ii. a capacidade de influência tem o potencial de afetar as liberdades individuais".

${ }^{13}$ Veja-se que mesmo em mercados tradicionais os modelos não são infalíveis. Tome-se, por exemplo, o caso Nestlé-Garoto, que Guerriero (2008, p. 3) destaca como o primeiro no Brasil a utilizar amplamente simulações baseadas em modelos econômicos na análise e como critério de decisão A diferença de premissas adotadas e o peso concedido a cada variável possibilitou resultados diversos, com enfoques diferentes sobre os efeitos do ato de concentração entre as companhias. Ainda que, nessa oportunidade, o CADE tenha se atentado para as similaridades entre os estudos apresentados pelas partes para tomar uma decisão, em outras situações é provável que isso não ocorra. Tendo em vista a crescente de cenários de incerteza envolvidos na análise antitruste, inclusive, é possível prever que a utilização de modelos diferentes poderá se mostrar uma dificuldade adicional para a autoridade.
} 
O intuito é possibilitar a manutenção de um cenário que se aproxime o máximo possível da concorrência - ainda que a realidade demonstre a formação de estruturas concentradas em alguns casos e de difícil desconcentração.

Por vezes, isso leva ao discurso de adoção de simplificação de regras e aplicação de modelos econômicos para a tomada de decisão do órgão judicante sobre a aprovação ou não de um ato de concentração como caminho ideal. Ao contrário do argumento jurídico, o uso da economia estaria isento de subjetividades retóricas e, de acordo com esse entendimento, forneceria certeza à decisão da autoridade quanto aos efeitos do ato de concentração. A aprovação ou proibição estaria, portanto, devidamente justificada.

Entretanto, conforme se demonstrou nas seções acima, o uso de modelos econômicos, apesar de apresentar um pavimento seguro para o trânsito das escolhas públicas, também não é infalível diante dos desafios do ambiente digital. Seus resultados são dependentes das premissas adotadas, bem como do ponto que se quer ressaltar, além das variáveis selecionadas pelo aplicador do modelo. Especialmente em mercados de inovação, nos quais preço, demanda e outros dados ainda não são possíveis de extração, a relação entre o uso da prova econômica segue em discussão nos principais fóruns internacionais e debates entre autoridades ${ }^{14}$.

Apesar disso, a análise econômica continua relevante no campo das provas. Por meio dela, ao deixar suas premissas e escolhas claras, as partes revelam tanto o posicionamento assumido quanto os pontos que querem destacar ao órgão judicante.

\section{Referências}

ARRUDA, Vivian Anne Fraga do Nascimento; PINEDO, Paula; MONDECK, Luísa Pereira. Direito Antitruste \& Inovação: mercados digitais envolvendo tecnologia disruptiva e análise antitruste. In: MACEDO, Agnes et. al. (Org). Mulheres no Antitruste. v. 1. São Paulo: Editora Singular, 2018, p. 34-47.

\footnotetext{
${ }^{14}$ Cf. Wu (2018), que critica a política antitruste atual aplicada às big techs; Pentagna (2018), sobre o crescimento da concentração econômica e do poder de mercado frente ao aumento significativo de markup nas economias desenvolvidas e sobre a dificuldade de aplicação do paradigma do bem estar do consumidor a plataformas gratuitas; e Khan (2017) sobre condutas anticoncorrenciais e prejudiciais aos consumidores nos mercados digitais. Relevante ressaltar a recente indicação aos órgãos de política concorrencial estadunidenses de Wu e Khan, indicando possíveis alterações no tratamento dado às big techs. Discussões prévias já ocorriam no Congresso norteamericano (BARTZ, GREBLER, 2019).
} 
BACCHI, Fabiana Mesquita; SCHAPIRO, Mario G. Análise dos atos de concentração no Brasil: forma, função e o incrementalismo reformista do CADE. In: CORDOVIL, Leonor; DE CARVALHO, Vinicius Marques; SCHAPIRO, Mario Gomes (Org.). Direito Econômico Concorrencial. 1 ed. v. 1. São Paulo: Saraiva, 2013, p. 49-96.

BARTZ, Diane; GREBLER, Dan Grebler. Congressional antitrust panel to discuss Big Tech competition. Reuters. Disponível em: https://www.reuters.com/article/us-usa-congresstech/ congressional-antitrust-panel-to-discuss-big-tech-competition idUSKCN1VO2D9. Acesso em: abril de 2021.

BORK, Robert H. The antitrust paradox. Nova Iorque: Basic Books, 1978.

CADE. Cartilha do CADE. Publicada em maio de 2016. Disponível em: http://www.cade.gov.br/acesso-a-informacao/publicacoes-institucionais/cartilha-do-cade. pdf/ view. Acesso em: dezembro de 2020.

COOTER, Robert; ULEN, Thomas. Law \& Economics. 6 ed. Boston: Addison-Wesley, 2012.

DE ANDRADE, José Maria Arruda. Da interpretação à argumentação jurídica: as armadilhas do essencialismo. In: GREGÓRIO JÚNIOR, Eduardo Lourenço; LEAL, Sal Tourinho (Org.). A Constituição Cidadã e o Direito Tributário: estudos em homenagem ao Ministro Carlos Ayres Britto. Belo Horizonte: Fórum, 2019, p. 285-308.

DE CARVALHO, Angelo Gamba Prata; FRAZÃO, Ana. O Ato de Concentração Itaú/XP e as Plataformas Digitais dos Efeitos de Rede à Influência Relevante. In: BAGNOLI, Vicente; CRISTOFARO, Pedro Paulo Salles (Coord.). Jurisprudência do CADE: comentada. São Paulo, RT, 2019, p. 29-48.

DOMINGUES, Juliana Oliveira; GABAN, Eduardo Molan; MIRANDA E SILVA, Breno Fraga. Direito Antitruste 4.0. e o abuso de posição dominante nos mercados digitais: um desafio atual para o CADE. Opinião \& Análise. Jota. Publicado em 17 de dezembro de 2018. Disponível em: https://www.jota.info/opiniao-e-analise/artigos/direito-antitruste-4-0-eoabuso-de-posicao-dominante-nos-mercados-digitais-17122018. Acesso em: janeiro de 2021.

DOMINGUES; Juliana. Big Techs e o Direito Antitruste. Opinião Folha de S. Paulo. 13 de junho de 2019. Disponível em: https://www1.folha.uol.com.br/opiniao/2019/06/big-techs-eodireito-antitruste-40.shtml. Acesso em: junho de 2019. 
DOMINGUES, Juliana O.; GABAN, Eduardo M. Livre Iniciativa, Livre concorrência e Democracia: valores Constitucionais indissociáveis do Direito Antitruste? In. NUSDEO, Fabio. (Coord.); PINTO, Alexandre Evaristo. A Ordem Econômica Constitucional: estudos em celebração ao $1^{\circ}$ Centenário da Constituição de Weimar. São Paulo: RT, 2019, p. 111-130.

DOMINGUES; Juliana O.; SILVA, Breno F. M. A liberdade econômica tem limites? reflexões sobre a aplicação do princípio da livre iniciativa e da livre concorrência. In. RODAS, João Grandino (Org.). 30 anos da Constituição Federal. São Paulo: Ed. Cedes, 2019, p. 279- 300.

DOMINGUES, Juliana Oliveira; SILVA, Breno F. M. Fake News: um desafio ao antitruste? Revista de Defesa da Concorrência, Brasília, v. 6, n. 2, p. 37-57, nov./2018. Disponível em: https:// revista.cade.gov.br/index.php/revistadedefesadaconcorrencia/article/ view/411. Acesso em: abril de 2021.

DOMINGUES, Juliana Oliveira; GABAN, Eduardo. Direito Antitruste. $4^{a}$ ed. Saraiva. São Paulo, 2016.

DOMINGUES, Juliana Oliveira. KLEIN, Vinicius. Análise Econômica do Direito e Defesa da Concorrência: novos desafios. In. YEUNG, Luciana. (Org.). Análise Econômica do Direito: temas contemporâneos. São Paulo: Actual, 2020, p. 79-108.

DOMINGUES, Juliana Oliveira; GABAN, Eduardo Molan. Direito Antitruste e Poder Econômico: o movimento populista e "neo-brandeisiano". Revista Justiça do Direito. v. 33, n. 3, p. 222-244, set./dez. 2019.

GUERRIERO, Ian Ramalho. Modelos de simulação na análise antitruste: teoria e aplicação ao caso Nestlé-Garoto. Dissertação (Monografia) - SEAE. São Paulo, 2008.

KATZ, Michael L. Big Tech mergers: innovation, competition for the market, and the acquisition of emerging competitors. Information Economics and Policy, vol. 54(C), mar./2021. Disponível em: https://ssrn.com/abstract=3624380. Acesso em: dezembro de 2020.

KHAN, Lina. Amazon's Antitrust Paradox. The Yale Law Journal, vol. 126, n. 3, p. 710805. 2017.

KWOKA, John. Controlling Mergers and Market Power: a program for reviving antitrust in America. 1 ed. Boston: Competition Policy International, 2020. 
LYRA, Marcos Puccioni de Oliveira. Inovação e efeitos de fusões e aquisições: contribuições da teoria econômica e a prática internacional. Dissertação (Mestrado em Economia) - Instituto de Economia, Universidade Federal do Rio de Janeiro, Rio de Janeiro, 2016.

MCCLOSKEY, Donald N. The Rhetoric of Law and Economics. Michigan Law Review, Ann Arbor, vol. 86. n. 4, p. 752-767, fev./1988.

MINISTÉRIO DA JUSTIÇA; MINISTÉRIO DA FAZENDA. Secretaria de Acompanhamento Econômico do Ministério da Fazenda e Secretaria de Direito Econômico do Ministério da Justiça. Portaria Conjunta SEAE/SDE $\mathbf{n}^{\mathbf{0}}$ 50, de $1^{\circ}$ de agosto de 2001. Brasília, 2001.

NUSDEO, Fábio. Curso de Economia: introdução ao direito econômico. 9 ed. São Paulo: Revista dos Tribunais, 2014.

PENTAGNA, Arthur Pinto. O antitruste na economia atual: uma discussão a partir dos questionamentos levantados pelos Neo-brandeisianos. Dissertação (Mestrado Profissional em Direito). Programa de Pós-Graduação em Desenvolvimento Econômico Universidade Federal do Paraná. Curitiba, 2019.

SATO, Cynthia Ayako. A eficiência como critério decisório na jurisprudência do CADE sobre atos de concentração. 2015. Dissertação (Mestrado em Direito) - Faculdade de Direito do Largo de São Francisco, Universidade de São Paulo, São Paulo, 2015.

SAITO, Leandro. Antitruste e novos negócios na Internet: condutas anticompetitivas ou exercício regular de poder econômico? 2016. Dissertação (Mestrado em Direito) Faculdade de Direito do Largo de São Francisco, Universidade de São Paulo, São Paulo, 2016.

WU, Tim. After Consumer Welfare, Now What? The 'Protection of Competition' Standard in Practice. The Journal of the Competition Policy International, 2018. Disponível em: https://ssrn.com/abstract=3249173. Acesso em: abril de 2021. 